\title{
Using a Clean Feedback Model to Facilitate the Learning Process
}

\author{
Barbara Walsh1, Sarah Nixon'1, Caitlin Walker², Nancy Doyle ${ }^{2}$ \\ ${ }^{1}$ School of Education, Leisure and Sport Studies, Liverpool John Moores University, Liverpool, UK \\ ${ }^{2}$ Training Attention Ltd., Liverpool, UK \\ Email: $\underline{\text { b.walsh@ljmu.ac.uk, s.nixon@ljmu.ac.uk, Caitlin@trainingattention.co.uk }}$
}

Received 20 May 2015; accepted 15 June 2015; published 19 June 2015

Copyright (C) 2015 by authors and Scientific Research Publishing Inc.

This work is licensed under the Creative Commons Attribution International License (CC BY).

http://creativecommons.org/licenses/by/4.0/

(c) () Open Access

\begin{abstract}
Effective and informative feedback is an essential part of learning and improving performance that is influenced by a number of issues, such as time constraints, ambiguous communication and emotional barriers (Hattie, 1998). Feedback should facilitate the learning process and the teaching performance. Accordingly, in this article we examine the "clean feedback" model developed by Walker and Doyle (2006) and explore its impact on the learning experiences of a purposeful sample of eleven beginning physical education teachers undertaking a one year postgraduate Qualified Teacher Status course at a post-92 university in the North West of England. After two days of staff and student training in using the model, the data in the form of lesson evaluations and self feed- back were collected at staged time intervals during their second placement school. The findings indicate that the model has improved the students' ability to give and receive both positive and negative feedback and to improve students self awareness and understanding of their own learn- ing and teaching styles. The implications of our findings are discussed in relation to the observation and feedback of the beginning teachers and mentors might be improved on such courses for physical education trainee teachers.
\end{abstract}

\section{Keywords}

Feedback, Feedback Model, Mentoring, Clean Language

\section{Introduction}

The context for this paper is that of teacher education. The authors, as teacher educators, are involved in assessing student teachers who in turn will be assessing themselves and the young people they teach. The students need to be able to experience different approaches to assessment and feedback and as such, the "clean feedback" 
model is introduced to raise awareness of feedback as a learning process.

According to Hattie and Timperley (2007), feedback on process and self regulation is more powerful than feedback about the task being assessed. It appears to have the most impact when goals are specific and challenging but the task complexity is low. Students are often dissatisfied with the feedback they receive, in terms of lacking specific advice to improve (Higgins, Hartley, \& Skelton, 2001), being difficult to interpret (Chanock, 2000) or having a potentially negative impact on students' self-perception and confidence (James, 2000). Detailed, specific, descriptive feedback which focuses students' attention on their actions it is suggested will help them to clearly identify what should happen next (Lipnevich \& Smith, 2009). Yorke (2003) further argues that, as well as the content of feedback, an awareness of the psychology of giving and receiving feedback is vitally important to student learning.

Beginning teachers often lack the confidence to reflect on their own teaching performance in the initial stages of their training, The less people believe in themselves, the more they need feedback (Race, 2001). Trying to incorporate giving as well as receiving feedback was a significant factor in introducing the concept of clean feedback to the novice teachers, who often found it difficult to give themselves feedback on their developmental needs. Through using clean feedback, the aim is to provide a broad context within which they come to understand what is working well as well as what is not working so well and what they ccn change. Participants were eleven student teachers of physical education on a one-year postgraduate Qualified Teacher Status course. All students were volunteers and gave written informed consent for the use of their data. The sample consisted of five males and six females, with an average age of 22.4 years old. Students initially attended a two-day training programme where they were introduced to the principles of the clean feedback model. Here, they were also invited to reflect on their preferred patterns of teaching and learning and how this might impact on the process of giving and receiving feedback.

\section{The Clean Feedback Model}

This "clean feedback" model was designed by Caitlin Walker and Nancy Doyle of Training Attention in 2003. Their background is in business coaching, where the quality of feedback was an issue. There was a dissatisfaction with the models available and therefore they designed the model to allow them to give positive and negative feedback but also to provide a developmental task as Levy and Williams (2004) proposed in business contexts that managers often hated giving feedback, they tended to edge around negative issues, over-generalize and fail to give sufficient details of what is required to improve. The "clean feedback" model aims to provide a structure for high quality, clear, task-level feedback, it is sensory specific, that is, it refers the individual to what they have seen or heard through their senses, rather than what they have made up or interpreted from data. A learner needs to know exactly how they did something wrong, so that they can avoid the behavior in the future. Equally, how exactly did they do the task correctly, so they can repeat it?

The structure for the model is shown below in the triggers provided as a framework as follows:

- Something that you said or did that worked well for me was .......;

- I interpret this as meaning .....;

- Something that you said or did didn't work so well so for was ...;

- I interpret this as meaning;

- Something I would have preferred you to say or do was ...;

- I would have interpreted this as meaning ...

The process within this model requires the sender of the feedback consciously to collect the sensory based information (what they are actually seeing or hearing) that is being used to form subjective judgments and to separate these out from the overall performance. For example, if you say "I was enthusiastic", this is your judgment, your inference. If you say that you noticed the observee smiled a lot, walked up and down the class and used a fast paced tone of voice and from this you inferred that I was enthusiastic; this is separating what I presented from what you interpreted. Rather than trying to decide things about the observee from example (s) of performance, the observer is giving a detailed account of the reaction to what was done or not done. This shifts the perception of the feedback from objective to subjective, and means that whilst the feedback given is highly individual, it is also representative of what other people similarly might think. Most importantly, by giving clear, behaviourally based information about what was actually said or done, the observee could choose to replicate or change behaviour in response to feedback. The observee does not have to accept the judgment but can make the decisions to build or break rapport with the observer once feedback has been received. In physical education, in- 
trinsic motivation can increase competence and the use of regular, specific feedback can enhance pupils progress (Kyriacou, 1998) and it can be argued that this can be similarly the case within the teacher education context.

\section{Method}

In order to learn about the clean feedback model, students received training on observation skills and being able to distinguish between information that was presented and inferred (Walker \& Doyle, 2006). They were encouraged to notice and articulate specific details in body language, tone of voice and phraseology that led to the inferential conclusions about what observers did or did not like. The following are some examples of feedback that was given.

\section{Feedback set 1}

"You weren't aware of the groups needs".

"You were friendly and welcoming".

"Your had a commanding style".

With the feedback in set 1 there is no way of replicating or avoiding the behaviour. Compare it to the following:

\section{Feedback set 2}

"You talked with your back to the group while you wrote on the board which meant some people couldn't hear you. My interpretation of that was that you were not aware of the group's needs in being able to hear you from the back".

"You smiled and introduced yourself personally to each pupil as they came in the room. That felt warm and welcoming to me".

"You spoke very quickly and loudly at first, whilst standing up, which caught their attention straight away.

The observer could then draw conclusions from the experience and subsequently offer some learning points for the observee, such as:

1. Talking with one's back to the group is perceived as being inconsiderate;

2. Personal introductions and smiling is friendly and;

3. Standing, whilst talking loudly gets attention at the start of a lesson.

The students also received support in finding out about their own learning styles and teaching styles in order to begin noticing patterns in the type of information they were likely to pick up on when giving and receiving feedback.

\subsection{Impact}

During the first eight weeks of their second placement in school the students submitted self-evaluations and lesson evaluations to the three members of staff involved in the training. These were sent on a fortnightly basis with some examples of the feedback they had given either to themselves as part of their reflective practice or to the pupils they had been teaching and this was assessed against the model and sent back with comments and clarifications.

The students then used this information in helping them to improve the quality of their own feedback. A third training day was arranged half way through the project where the students participated in further developmental activities to understand their own preferences in their learning and teaching styles and those of their peers, to better understand how these impacted on the feedback they gave and received. A final developmental session was completed at the end of the project to enable students to share their experiences with the clean feedback model, to identify what developmental tasks they could set themselves having gone through the programme and to consider how best to develop their uses of it in the future.

At the end of the final training session, each student was asked to complete a questionnaire addressing their use of and interaction with the feedback model and this was analyzed to determine the students' perceptions of the experience. They were asked to assess themselves about their self awareness when they delivered a successful lesson and their learning and reflection from this. The questionnaire was a mixture of open and closed questions and resulted in both quantitative and qualitative analysis. A focus group was also undertaken at the end of the project, in which five of the students took part, where further details and clarification were sought around issues surrounding the clean feedback model. The five students who participated in the focus group were randomly chosen using alternate alphabetical surnames. 


\subsubsection{Effectiveness of the Process in Developing Good Practice to Become a Teacher}

The results indicate that the training as a whole was regarded by the students as being "useful" for their own learning and teaching processes with none selecting "not at all useful" from the options. In relation to their learning, the students reported receiving feedback from others about themselves was more useful than the feedback they gave to others. This links in with the work of Ovando (1994) where feedback is seen as not a freestanding piece of information but part of the learning context where all protagonists need to be engaged in the process. This changes when the emphasis is on teaching where feedback from others takes on a slightly greater significance.

The results suggest that there is strength in the process related to the development of the feedback both from and to others, possibly depending on the context. The responses to the open-ended questions support this view. Here, three main themes emerged related to development of self awareness and understanding, ability to listen more clearly and the ability to distinguish between presented and inferred material.

One student commented that:

"The process has given me a great insight into the fact that, just because I understand what I mean, not everyone will, as everyone see things differently".

Another looked at their understanding of their own patterns of behaviour:

"I have a better understanding of what I need to do in order to work at my best-the environment I need to create and the mentality I need to have. It has made me more aware of my own traits which can then be recreated in order to make me more productive".

Further comments related to learning from others and observing and copying patterns of behaviour:

“I am starting to observe traits in individuals' body language so that I can recreate it in my teaching”.

Another student looked at communication issues and related this to feedback:

"It has made communication easier, in the sense that I am conscious to not infer somebody's response to a question or situation and helps me to understand them better as individuals. I also appreciate the process much more considering I am constantly on the receiving end of feedback in school”.

Overall the results in this section show an emphasis on the importance of listening and learning from others, but comments are mainly framed in terms of personal benefits: "in order that I may understand". There appears to be a bias within these results towards self benefits and most answers concern how this training has affected their own knowledge about their training, rather than what that training might do for others (Hattie \& Timperley, 2007). This is evidenced in the following comment:

“The whole process has opened my eyes to different teaching and learning styles and different ways to communicate in order to assist individuals in their learning but also in their appreciation of other's strengths and weaknesses".

This would seem to fit the commonly noted student needs at this stage in their training. One student talked about how the use of the model has enabled them to expand their own experiences:

“The Model is crisp and it also makes you realise what is important to you, I didn't actually recognise how important good behaviour was to me until I started using that model and then it became apparent that actually it was something that I put down so often that it is obviously quite important”.

The model has helped the student generate internal feedback against the backdrop of external goals related to the environment against which they can set themselves their own performance indicators (Macfarlane-Dick 2006). It is important for student teachers to become self-regulated learners. The clean feedback model helps to generate internal feedback about the degree to which the student teachers are reaching these goals and what they need to do to improve progress towards them. According to Zimmerman and Schunk (2001), these types of learners are more persistent, resourceful, confident and higher achievers.

\subsubsection{Effectiveness in Giving and Receiving Feedback Using the Clean Feedback Model}

Newly Qualified Teachers as well as experienced teachers often find it difficult to perform the task of teaching 
and at the same time to monitor their own performance of that task (Ellis, 2007). As most practising teachers acknowledge, they can easily convince themselves that they have just delivered the perfect lesson and without focused feedback, the learning curve of self evaluation will plateau.

Although there is evidence that some students perform better having had instruction rather than feedback on poorly understood concepts (Hattie \& Timperley, 2007; Orsmond, Merry, \& Reiling, 2002) the literature suggests that clear, usable feedback will improve performance and aid learning. This is a "double edged sword" (Kluger \& DeNisi, 1998), as poor quality feedback can impede learning and set back performance.

The ability to observe behaviour is a key component of feedback and is crucial in the effectiveness of the use of any feedback system (Sadler, 1989; Audia \& Locke, 2003; Brinko, 1993). The difference in learning outcomes for the sender and receiver of clean feedback means that the model gives the receiver information at the task/behavioural level (Kluger \& DeNisi, 1998), and the sender gets information about their own traits.

\subsection{Observational Skills}

The observational aspect of the students on the training seemed to have the greatest impact on self awareness. This links with the majority of the findings in the first section of this paper related to self development. The second most reported impact is that mentors and colleagues have the least impact on learning observational skills when observing pupils, with the following student comment illustrating the link between the ability to observe and the information that is then needed in order to give and receive feedback: "The observation process was most useful as I use it to determine the facts from inference".

With giving and receiving feedback, more impact is reported on pupil learning and self evaluation, however, the results would seem to indicate that the training has been helpful for working with all of the highlighted groups.

One student stated:

"What I think works well with it is the fact that you are giving the pupils a reason behind what you are saying, so you are telling them that they are good but you are telling them why and then you are telling them what they can improve and why and they appreciate that a lot more instead of saying you did that right and that's it and you did that wrong and they don't know why".

In relation to giving feedback in particular, one student noted that: "It has given me a focus to provide constructive sensitive feedback that is useable for the receiver". Again these student comments highlight the importance of self awareness; with one student noting how they are using the process: "When I have a successful lesson it is easier to ascertain why; now that I know the right formula to work through (and vice versa after a poor lesson)". Another used the feedback in a number of ways:

"I used the feedback model rather than using the evaluation forms from UNI for each lesson observation, both for myself and observing a mentor, it's a way of logging good practice, or the scenario for my own benefit in the future if I ever come across anything like that".

As part of the project, the students submitted some of their own attempts at feedback for scrutiny and this was commented on, in relation to its alignment with the clean feedback model. Across their second placement the students were consistently able to use the clean feedback model when giving information about what they liked, or what worked well for them. However, they were less adept at using the model for information about what they did not like. This links to the findings of Benedict and Levine (1988), who find that most people avoid giving negative feedback. Podsakoff and Farh (1989) reported that positive feedback could produce complacency and that negative feedback was the catalyst to remedy a deficiency. However, the participants did improve on their ability to apply the model to negative feedback, which might longer term improve the effectiveness of their feedback overall, as they are now better able to give positive and negative feedback in equal measures (Molden, 2007). When considering what they would prefer instead, most of the students considered they had developed their abilities to feedback about this over the time period.

As mentioned above one of the areas within feedback that is often seen as an issue (Benedict \& Levine, 1988) is related to giving and receiving negative information. The qualitative information generated in this study suggests that the use of the model makes this easier for the students. As one student commented:

"When having to give messages that were not so easy, I found that by using the model you can clearly explain what it is you didn't like and use examples to demonstrate what you are saying”. 


\section{Another stated that:}

"I felt much happier with my mentor in relation to giving feedback on their teaching as I could give actual examples and tell them what it meant to me. I was actually able to get more of the point across, and I said much more than I would normally have said”.

The structure of the model enables the different experiences to be broken down and one student stated that:

"By using the model, I have been able to break down what I have liked/what I have not [liked] when observing others, giving me a clearer understanding of the positives and negatives".

These results indicate it is argued that the model is clearly useable and learnable. Once learned, it means the students are able to clearly state what they observed and how they interpreted it, diminishing the receiver's need for “cognitive elaboration” (Audia \& Locke, 2003).

\subsection{Perceptions of the Usefulness of the Procedure}

Students at this stage of their Postgraduate programme normally had very large workloads and steep learning curves, so this project was seen at times as additional work and this caused some issues with the individuals giving focused time to their development of the skill set. Ramsden (2003) argues that effective comments on students' work represent one of the key characteristics of quality teaching. One student noted:

"It has been difficult as we have had to deal with a lot of things this year; there has been a lot of pressure on us. I used it with my mentor in my first placement a lot, because he was very open to the fact there were many ways of doing things but in my second placement it hasn't really had the impact”.

However, there were a large number of other benefits that were not seen as part of the initial working through of the model but were commented on subsequently. Students noted such things as their abilities to use skills learned while using the model in other areas of work and life, improved communication development, enhanced confidence, and better abilities to be observant. One stated that, "My confidence in expressing myself to a group of people has improved, allowing me to understand more about myself and others".

Overall the results indicate that the clean feedback model and the processes around developing the skills in this area can be very effective for students as they develop their capabilities as teachers. As one of them commented in support of this view:

"Now, when I ask a question I wait for a response and listen to the answer rather than trying to finish someone's sentence for them in order to let them know that I understand. It helps me understand individuals and their own needs in terms of how they learn at their best but also what is important to the teachers observing me, making the process of being a novice eteacher much easier, adjusting each lesson according to what each teacher expects, and in turn broadening my experience and taking different traits from each teacher".

\section{Conclusions}

The use of feedback is a mature research topic within the discourses of education, organizational psychology and management studies. In much of the research literature involving the assessment process, feedback is potentially the most important and powerful part that affects future student learning (Hattie, 1997; Black \& Wiliam, 1998; Gibbs \& Simpson, 2004). For example, Sadler (1989) highlights the view that quality feedback can help the learner identify learning gaps between their current level of achievement and a desired level, supporting them in closing this gap. Likewise, Higgins et al. (2002) argue, "feeding forward", that is, projecting towards the next assignment when giving feedback on the last, enhances the effectiveness of "feeding back".

Against this backdrop, this study has taken the Clean Feedback model and associated training and worked with beginning teachers in a work-based environment. A number of findings have been highlighted with the overall conclusion being that even at this initial level of learning about clean feedback, the learning can be multi-directional and effective for both sender and receiver.

The findings, from this small scale study, have indicated that this model is learnable and, by implication, teachable within the framework of teacher training and is of great use to trainee teachers of physical education in the context within which they work. Highlighted areas have been shown to be focused predominantly on per- 
sonal development but other types of development are also evident. Associated benefits have been around enhancing environmental awareness, communication, listening skills and general good work practices. Learning the model has been seen to improve students' self awareness and understanding of their own learning and teaching styles.

The clean feedback model can be used alongside the Nicol and Macfarlane-Dick (2006) model of 7 principles of good feedback where stage one is clarifying what good performance is, facilitating the development of reflection and self assessment in learning and delivering high quality feedback that enables them to self reflect, this in turn encourages student teacher and peer dialogue around teaching. Nicol and Macfarlane-Dick (2006) explain that if this happens it encourages positive motivational beliefs and provides opportunities to act on the feedback which can help to shape their future teaching. The clean feedback model has encouraged the small sample of students in this study to develop a greater awareness and understanding of themselves, colleagues, pupils and mentors and may support the development of systemic thinking. Maclellan (2001) argues that, unless students are monitoring and regulating the quality of their own learning, feedback in itself, regardless of the degree of detail, is unlikely to generate improvement in learning. Learning this model has improved students' abilities to give and receive both positive and negative feedback. Ovando (1994) found that feedback should be relevant, timely, factual helpful, confidential, respectful, tailored to specific needs and encouraging. Student teachers and teachers who receive this type of relevant feedback are more likely to be successful as they engage in the teaching and learning process.

\section{References}

Audia, P. G., \& Locke, E. A. (2003). Benefiting from Negative Feedback. Human Resource Management Review, 13, 631646. http://dx.doi.org/10.1016/j.hrmr.2003.11.006

Benedict, M. E., \& Levine, E. L. (1988). Delay and Distortion: Tacit Influences on Performance Appraisal Effectiveness. Journal of Applied Psychology, 3, 507-514. http://dx.doi.org/10.1037/0021-9010.73.3.507

Black, P., \& Wiliam, D. (1998). Assessment and Classroom Learning. Assessment in Education, 5, 7-74. http://dx.doi.org/10.1080/0969595980050102

Brinko, K. T. (1993). The Practice of Giving Feedback to Improve Teaching: What Is Effective? The Journal of Higher Education, 64, 574-593. http://dx.doi.org/10.2307/2959994

Chanock, K. (2000). Comments on Essays: Do Students Understand what Tutors Write? Teaching in Higher Education, 5, 95-105. http://dx.doi.org/10.1080/135625100114984

Ellis, V. (2007). Learning and Teaching in Secondary Schools (3rd ed.). Exeter: Learning Matters Limited.

Gibbs, G., \& Simpson, C. (2004). Conditions under Which Assessment Supports Students’ Learning. Learning and Teaching in Higher Education, 1, 3-31.

Hattie, J. A. (1997). Setting Standards for Beginning Teachers: A Discussion Paper. Washington DC: National Council for Accreditation of Teaching Standards.

Hattie, J. A., \& Jaeger, R. (1998). Assessment and Classroom Learning. A Deductive Approach. Assessment in Education, 5, 111-122. http://dx.doi.org/10.1080/0969595980050107

Hattie, J. A., \& Timperley, H. (2007). The Power of Feedback. Review of Educational Research, 77, 81-112. http://dx.doi.org/10.3102/003465430298487

Higgins, R., Hartley, P., \& Skelton, A. (2001). Getting the Message Across: the Problem of Communicating Assessment Feedback. Teaching in Higher Education, 6, 269-274. http://dx.doi.org/10.1080/13562510120045230

Higgins, R., Hartley, P., \& Skelton, A. (2002). The Conscientious Consumer: Reconsidering the Role of Assessment Feedback in Student Learning. Studies in Higher Education, 27, 53-64. http://dx.doi.org/10.1080/03075070120099368

James, D. (2000). Making the Graduate: Perspectives on Student Experience of Assessment in Higher Education. In A. Filer (Ed.), Assessment: Social Practice and Social Product. London: Routledge.

Kluger, A.N., \& DeNisi, A. (1998). Feedback Interventions: Towards the Understanding of a Double Edged Sword. Current Directions in Psychological Science, 7, 67-72. http://dx.doi.org/10.1111/1467-8721.ep10772989

Kyriacou, C. (1998). Essential Teaching Skills (2nd ed.). Cheltenham: Stanley Thornes.

Levy, P. E., \& Williams, J. R. (2004). The Social Context for Performance Appraisal: A Review and Framework for the Future. Journal of Management, 30, 881-905. http://dx.doi.org/10.1016/j.jm.2004.06.005

Lipnevich, A. A., \& Smith, J. K. (2009). “I Really Need Feedback to Learn”: Students’ Perspectives on the Effectiveness of the Differential Feedback Messages. Educational Assessment, Evaluation and Accountability, 21, 347-367.

http://dx.doi.org/10.1007/s11092-009-9082-2 
Maclellan, E. (2001). Assessment for Learning: The Differing Perceptions of Tutors and Students. Assessment and Evaluation in Higher Education, 26, 307-318. http://dx.doi.org/10.1080/02602930120063466

Molden, D. (2007). Managing with the Power of NLP. Upper Saddle River, NJ: Prentice Hall.

Nicol, D., \& Macfarlane-Dick, D. (2006). Formative Assessment and Self-Regulated Learning: A Model and Seven Principles of Good Feedback Practice. Studies in Higher Education, 31, 199-218. http://dx.doi.org/10.1080/03075070600572090

Orsmond, P., Merry, S., \& Reiling, K (2002). The Student Use of Formative Feedback in Their Learning. Paper presented at the Learning Communities and Assessment Cultures Conference, University of Northumbria, 28-30 August 2002.

Ovando, M. N. (1994). Constructive Feedback: A Key to Successful Teaching and Learning. International Journal of Education Management, 8, 19-22. http://dx.doi.org/10.1108/09513549410069185

Podsakoff, P. M., \& Farh, J.-L. (1989). Effects of Feedback Sign and Credibility on Goal Setting and Task Performance. Organisational Behaviour and Human Decision Processes, 44, 45-67. http://dx.doi.org/10.1016/0749-5978(89)90034-4

Race, P. (2001). Using Feedback to Help Students Learn. New York: Higher Education Academy.

Ramsden, P. (2003). Learning to Teach in Higher Education (2nd ed.). London: Routledge.

Sadler, R. (1989). Formative Assessment and the Design of Instructional Systems. Instructional Science, 18, 119-144. http://dx.doi.org/10.1007/BF00117714

Walker, C., \& Doyle, N. (2006). Accessed 9 May 2012. www.trainingattention.co.uk

Yorke, M. (2003). Formative Assessment in Higher Education: Moves towards Theory and the Enhancement of Pedagogic Practice. Higher Education, 45, 477-501. http://dx.doi.org/10.1023/A:1023967026413

Zimmerman, B. J., \& Schunk, D. H. (Eds.) (2001). Self-Regulated Learning and Academic Achievement: Theoretical Perspectives (2nd ed.). London: Routledge. 